Pilot implementation of psychoeducational workshops on behavior management and stress management for parents and teachers

Katerina Baeza-Hernandez, B.S., Meagan Lasecke, B.S., Alyssa Herman, B.A., Jenna Kim, B.A., Jessica M. J. Lin, B.A., Gilly Dosovitsky, M.S., Eduardo L. Bunge, Ph.D., Alayna L. Park, Ph.D.

Palo Alto University

Note: This manuscript is currently under peer review (resubmission date: April 21, 2022). Please do not cite without the authors' permission. 


\begin{abstract}
Author note
Correspondence concerning this manuscript should be addressed to Alayna Park, Ph.D., Department of Psychology, University of Oregon, 1227 University of Oregon, Eugene, OR 97403. Email: alaynap@uoregon.edu. Twitter: @ ALParkPhD

Acknowledgements: We wish to acknowledge the dedicated principals, teachers, and staff at the Mountain View Whisman School District who supported this research with their time, effort, and enthusiasm. We also wish to thank Sonia Gomez, Claudia Olaciregui, Heidi Galassi, and Michelle Williams (Mountain View Whisman School District), as well as Alejandra Torres Sanchez (Children's Hospital Los Angeles) for their support of this work.

Funding statement: The authors received no specific funding for this work.

Disclosure statement: The authors declare that they have no conflict of interest.

Data availability statement: The data that support the findings of this study are available from the corresponding author, AP, upon reasonable request.
\end{abstract}




\begin{abstract}
The COVID-19 pandemic created compounding stressors for school-aged children, parents, and teachers and underscored the urgent need to widely implement evidence-based programs for promoting youth mental and behavioral health. In two community-engaged studies, we piloted psychoeducational workshops that taught behavior management and stress management strategies to parents and teachers. The research team partnered with a northern California school district to develop and implement these psychoeducational workshops. In study 1 , parents $(N=165)$ participated in a series of workshops on behavior management. Parents perceived the strategies covered in each workshop to be acceptable, appropriate, and feasible and were able to accurately describe behavior management strategies following each workshop. In study 2 , teachers $(N=113)$ participated in workshops on behavior management and stress management. Teachers perceived the strategies covered in each workshop to be acceptable, appropriate, and feasible and were able to accurately describe the strategies following each workshop. Findings suggest that psychoeducational workshops may be a promising avenue for promoting youth mental and behavioral health. Lessons learned from conducting this community-engaged research are discussed, as well as future directions for widely implementing psychoeducational workshops for parents and teachers.
\end{abstract}




\section{Pilot implementation of psychoeducational workshops on behavior management and stress management for parents and teachers}

The public health, social, and economic consequences of the COVID-19 pandemic are anticipated to be felt for a generation (Gruber et al., 2020). To mitigate the rapid spread of the virus, school districts across the United States shifted to online learning (i.e., suspension of inperson learning, distribution of technology-facilitated learning materials, fully remote school operations). This sudden shift created technological, pedagogical, and logistical challenges for all involved parties and compounded the pandemic's mental and behavioral health impact on students, parents, and teachers (American Psychological Association [APA], 2021; Schlegelmilch \& Douglas, 2020). Children and adolescents reported lower quality of life and increased mental health problems, including worsened anxiety, depressive, and psychosomatic symptoms (Ravens-Sieberer et al., 2021, Rosen et al., 2021). Parents reported increased

symptoms of depression and anxiety throughout the pandemic (Brown et al., 2020). Additionally, teachers reported high rates of stress and burnout as a result of adapting their curriculum to online learning, coordinating online learning with parents, and providing both administrative and technical support in addition to their usual teaching responsibilities (Pressley, 2021).

The mental health services literature has identified several prevention strategies that could help mitigate some of the mental and behavioral health consequences of the pandemic. For example, behavioral management strategies, which have strong research support for addressing youth disruptive behaviors (Boustani et al., 2020), could help promote youth well-being and positive parent-child interactions when navigating the stress and uncertainty of the pandemic. However, the general public largely lacks requisite knowledge on how to recognize mental and behavioral health problems (Jorm et al., 2006), let alone how to effectively respond to these 
problems when they arise (Kelly et al., 2007). These deficiencies in mental health literacy serve as a barrier to seeking professional help and to using effective prevention strategies (Gulliver et al., 2010; Jorm, 2012).

Psychoeducational interventions, particularly those based in educational settings, have been recommended for enhancing the general public's mental health literacy (Jorm, 2012; Kelly et al., 2007). Psychoeducation (i.e., the process of providing factual information about mental health problems and effective treatment options, Martinez et al., 2017) has been shown to improve engagement in mental health services, use of coping skills, and overall mental health outcomes (Taylor-Rodgers \& Batterham, 2014). Given the integral roles that parents and teachers play in the lives of youth, teaching parents and teachers to recognize and respond to youth mental and behavioral health problems has the potential to promote universal well-being and functioning. Decreasing youth behavioral health problems can also decrease parental stress, which in turn, can lead to further improvements in youth well-being and functioning (Neece et al., 2012; Osgood et al., 2021). Accordingly, enhancing parents and teachers' mental health literacy through psychoeducational interventions may help prevent youth mental and behavioral problems from having a lasting negative impact.

Implementation science, or the study of methods to promote the adoption of evidencebased interventions into public health settings, can help inform the successful delivery of psychoeducational interventions for parents and teachers. For example, the Exploration, Preparation, Implementation, Sustainment (EPIS) framework is a popular model for guiding and describing the implementation of evidence-based interventions (Aarons et al., 2011; Moullin et al., 2019). The EPIS framework proposes that implementation of evidence-based interventions is influenced by system context (e.g., school district leadership, online learning policies and 
procedures), organizational context (e.g., school climate, student and parent characteristics), bridging factors (e.g., community academic partnerships), and intervention factors (e.g., intervention fit with the school context), as well as four phases: Exploration (e.g., considering the needs of youth, caregivers, and teachers); Preparation (e.g., developing a plan to use an evidence-based intervention that will address the needs of youth, caregivers, and teachers); Implementation (e.g., using the intervention in the school); and Sustainment (e.g., continuing to use the intervention, with or without some adaptation).

Using the EPIS framework as a guide (see Figure 1), the research team partnered with a school district in northern California to develop and implement a series of psychoeducational workshops for promoting mental health and preventing emotional and behavioral problems, which were evaluated in two community-engaged feasibility studies. The first study aimed to evaluate the acceptability, appropriateness, feasibility, and comprehension of behavior management strategies covered in psychoeducational workshops for parents. The second study aimed to evaluate the acceptability, appropriateness, feasibility, and comprehension of stress management and behavior management strategies covered in psychoeducational workshops for teachers. In the exploration phase, the research team met with school principals per their request to understand the mental health needs of their school (see Lasecke et al., 2022 for more details about this community academic partnership). In the preparation phase, the research team collaborated with stakeholders to develop workshops focused on teaching parents and teachers to recognize and respond to disruptive behavior problems and psychological stress, which were likely exacerbated by stressors related to COVID-19. In the implementation phase, members of the research team delivered these interactive workshops in English and Spanish via a video conferencing platform. The research team considered the system context, organizational context, 
and intervention factors across these phases (e.g., centering the workshops around evidencebased mental and behavioral health promotion strategies, including examples for managing stressors related to the COVID-19 pandemic). Through understanding parents and teachers' responses to psychoeducational workshops developed by community academic partners from exploration to implementation, we sought to elucidate opportunities for promoting well-being in schools.

\section{Study 1}

\section{Method}

\section{Participants}

Four elementary and middle schools from a northern California suburban school district partnered with the research team to implement a series of behavior management workshops for parents (Table 1). As of June 2020, the district served 5,382 students across 11 elementary and middle schools, with $32 \%$ of those students in a free or reduced lunch program. Students enrolled in the school district identified as White (37\%), Hispanic/Latino (33\%), and Asian (26\%) (see Table 1 for student race/ethnicity by school).

\section{Measures}

The following measures were administered to assess organizational factors (i.e., youth mental health problems and school climate) and service and implementation outcomes (i.e., acceptability, appropriateness, feasibility, and comprehension of behavior management strategies). All measures were available in English and Spanish. Measures were first translated from English to Spanish by a member of the research team, and then backward translated from Spanish to English by another member of the research team. Both translators were fluent in English and Spanish. The English translations were compared with the original English versions 
and inspected for differences. In the event of a discrepancy, the translators consulted with one another to agree upon mutually acceptable wording.

Youth Mental and Behavioral Health Problems. The Behavior and Feelings Survey is a 12-item parent-report measure that assesses youth emotional and behavioral problems along three subscales: internalizing problems, externalizing problems, and total problems. This measure prompts respondents to rate emotional and behavioral problems from 0 (not a problem) to 4 (a very big problem). Subscale scores are calculated by summing item scores. This measure has demonstrated robust factor structure, internal consistency, test-retest reliability, convergent and discriminant validity (Weisz et al., 2019).

School Climate. The New Jersey School Climate Survey is a parent-report measure that assesses school climate (i.e., impressions of the school, such as the supportiveness of the learning environment). To reduce participant burden, this study focused on the 9-item Parental Support and Engagement subscale, which assesses the extent to which degree to which parents and community members are incorporated into both the social and academic life of the school. Subscale scores range from 0 to 100 , with higher scores indicating greater satisfaction with the school. The New Jersey School Climate Survey has demonstrated explanatory validity, predictive validity, comparative model fit, and internal consistency (New Jersey Department of Education, 2014).

Acceptability, Appropriateness, and Feasibility. The Acceptability of Implementation Measure (AIM) assesses the extent to which individuals perceive an intervention (i.e., for this study, the strategies covered in the psychoeducational workshops) to be agreeable, palatable, or satisfactory. The Intervention Appropriateness Measure (IAM) assesses the extent to which individuals perceive an intervention to fit a particular context. The Feasibility of Intervention 
Measure (FIM) assesses the extent to which individuals perceive that an intervention can be successfully used. These three 4-item measures prompt respondents to rate their agreement with statements about the intervention from 1 (completely disagree) to 5 (completely agree). Higher average scores indicate greater acceptability, appropriateness, and feasibility, respectively. Each measure has demonstrated substantive and discriminant content validity, structural validity, known-groups validity, test-retest reliability, and sensitivity to change (Weiner et al., 2017).

Comprehension. To assess comprehension of workshop content, participants were asked to provide written responses to the question, "What is the most important thing you learned from this workshop?" This question was derived from the Service Review Measure, a client-report measure of psychotherapy session content (Regan, 2014).

\section{Psychoeducational Workshops}

The research team and school staff (i.e., principals, school counselors, and other administrators) collaboratively developed a series of five behavior management workshops (Table 2). Each workshop focused on independent behavior management strategies that could stand alone or build off of one another. The first workshop provided psychoeducation about disruptive behavior problems and guidance on how to give effective instructions. The second workshop provided psychoeducation on antecedents, behaviors, and consequences and further guidance on how to give effective instructions and praise appropriate behaviors. The third workshop taught parents how to attend to appropriate behaviors, ignore inappropriate behaviors, and set household rules. The fourth workshop taught parents how to punish noncompliance and aggression, as well as how to engage in problem solving. The fifth workshop reviewed the behavior management strategies covered in previous workshops and provided psychoeducation on when and how to seek professional help. 


\section{Procedures}

All study procedures were approved by the institutional review board of Palo Alto University. In the fall of 2020, the school district recognized the challenges that parents were facing and requested psychoeducational workshops for parents (Exploration phase). Staff at four schools partnered with the research team to collaboratively develop a series of five workshops (Preparation phase). The research team created PowerPoint presentations for each psychoeducational workshop and presented via a video conferencing platform (Implementation phase). The presentations were designed to be interactive and prompted parent participants to discuss how they could apply the behavior management strategies within their households. As an example, parents were asked how they might respond to their child throwing a temper tantrum and whether their response would reinforce or extinguish their child's disruptive behaviors. Workshops were led by clinical psychologists and clinical psychology doctoral students. Based on recommendations from school staff, workshops were scheduled for mornings after school drop-off or evenings. Each workshop was scheduled to be one hour in duration. All workshops were offered in English and Spanish. Each participating school received three to nine workshops based on their support, scheduling, and language needs. Workshop enrollment was open, such that parents could drop into any workshop regardless of previous workshop attendance. After each workshop, parent participants were invited to complete a questionnaire hosted through the Qualtrics online survey platform on youth mental and behavioral problems, school climate, and acceptability, appropriateness, feasibility, and comprehension of behavior management strategies. Parent participants received a \$5 gift card upon completing the questionnaire. 


\section{Data Analyses}

The acceptability, appropriateness, and feasibility of the behavior management strategies covered in the psychoeducational workshops was assessed using descriptive statistics. Comprehension of the behavior management strategies was assessed by comparing behavior management strategies included in parent participants' responses of the most important thing they learned with strategies covered in the corresponding psychoeducational workshop. The most important things that parents learned were characterized using a theoretical thematic analytic approach. Two graduate students independently coded parent participants' responses for the behavior management strategies covered in the psychoeducational workshops. Agreement ranged from $86 \%$ to $100 \%$. Any discrepancies were resolved through consensus.

\section{Results}

Twenty-four workshops were conducted in English (13 workshops) and Spanish (11 workshops), with an average of 6.88 parents attending each workshop $(S D=4.18)$. Parents who completed the post-workshop questionnaire $(n=20)$ averaged 45.24 years $(S D=8.25)$ in age and identified predominantly as Asian (47\%) and White (47\%). Most parent participants identified as women (89\%) and reported having a family income above $\$ 75,000$ a year $(66 \%)$. Parents reported having one to three children $(M=1.72, S D=.57)$, ranging from 2 to 16 years old $(M=$ 9.03, $S D=3.60)$. On the Behavior and Feelings Survey, parents reported both youth internalizing problems $(M=5.60, S D=5.52)$ and externalizing problems $(M=7.97, S D=6.20)$, and $67 \%$ of parents reported that these problems had persisted for more than 6 months. The Parental Support and Engagement domain score on the New Jersey School Climate Survey was 82.7, indicating that parent participants felt incorporated into the social and academic life of the school. 
Parents perceived all workshop strategies to be acceptable (AIM $M=4.47, S D=.48$ ), appropriate (IAM $M=4.43, S D=.57)$, and feasible $($ FIM $M=4.31, S D=.47)$. Table 3 shows the attendance and perceived acceptability, appropriateness, and feasibility of the strategies covered in each workshop. Of the 17 parents who shared the most important thing they learned from the psychoeducational workshops, 5 referred to giving effective instructions, 3 referred to praising appropriate behaviors, 1 referred to setting household rules, and 1 referred to punishing inappropriate behaviors. Six parents reported learning things that would promote positive parentchild interactions (e.g., "Tools for building parent-child relationships"), and four parents reported learning things that were not specific to a particular behavior management strategy (e.g., "I loved the practical information and tips given").

\section{Study 2}

\section{Methods}

\section{Participants}

Two elementary and middle schools from a northern California suburban school district partnered with the research team to implement classroom management and stress management workshops for teachers (Table 1). As of June 2020, the district employed 310 teachers serving kindergarten through $8^{\text {th }}$ grade students across 11 schools.

\section{Measures}

Teacher perceptions of their school climate were assessed using the school staff version of the New Jersey School Climate Survey described in Study 1. Specifically, teachers completed the 5-item Parental Support and Engagement subscale, which assesses the degree to which parents are incorporated into the social and academic life of the school, and the 10-item Emotional Environment subscale, which assesses attitudes toward the social environment. 
Teachers also completed the AIM, IAM, and FIM measures described in Study 1 and were prompted to provide written responses to the question, "What is the most important thing you learned from this workshop?"

\section{Psychoeducational Workshops}

The research team and school staff collaboratively developed two psychoeducational workshops for teachers (Table 2). The classroom management workshop taught teachers how to give effective instructions and praise appropriate student behaviors. The stress management workshop provided psychoeducation about the relationships between thoughts, feelings, and behaviors and taught teachers how to restructure maladaptive thoughts. The psychoeducational workshops were led by a clinical psychologist and an advanced clinical psychology doctoral student. Based on recommendations from school staff, these workshops were hosted synchronously on a video-conferencing platform during staff meetings and were scheduled for 30 minutes to 1 hour.

\section{Procedures}

All study procedures were approved by the institutional review board of Palo Alto University. In the spring of 2021, staff from two of the schools that participated in Study 1 recognized the potential benefit of psychoeducational workshops for teachers (Exploration phase) and partnered with the research team to develop two workshops (Preparation phase). These workshops for teachers followed a similar design as the workshops for parents described in Study 1 (Implementation phase). After each workshop, teachers were invited to complete a questionnaire hosted through the Qualtrics online survey platform on school climate and acceptability, appropriateness, feasibility, and comprehension of behavior management and 
stress management strategies. Teacher participants received a \$5 gift card upon completing the questionnaire.

\section{Data Analysis}

The acceptability, appropriateness, feasibility, and comprehension of the classroom and stress management strategies covered in the psychoeducational workshops for teachers were examined using similar data analyses as Study 1. Agreement between two graduate students characterizing the most important thing that teachers learned ranged from $87 \%$ to $96 \%$, with any discrepancies resolved through consensus.

\section{Results}

A total of 113 teachers attended three workshops: one classroom management workshop at a middle school, and two stress management workshops at an elementary school and a middle school. Teachers who completed the post-workshop questionnaire $(n=52)$ averaged 40.00 years $(S D=10.76)$ in age. Teachers identified as women $(75 \%)$ and men $(25 \%) ; 69 \%$ identified as White, $10 \%$ as Asian, $10 \%$ as Hispanic/Latinx, and 10\% as multiracial. The Parental Support and Engagement domain score on the New Jersey School Climate Survey was 72.6, indicating that teacher participants felt that parents are incorporated into the social and academic life of the school. The Emotional Environment domain score on the New Jersey School Climate Survey was 66.7, indicating temperately positive attitudes about student behavior at school.

Teachers perceived all workshop strategies to be acceptable, (AIM $M=4.25, S D=1.01$ ), appropriate (IAM $M=4.34, S D=.89)$, and feasible $($ FIM $M=4.31, S D=.91)$. Table 4 shows the attendance and perceived acceptability, appropriateness, and feasibility scores for the strategies covered in each workshop. Of the 29 teachers who shared the most important thing they learned from the classroom management workshop, 18 nominated how to praise appropriate 
behaviors, 5 nominated how to give effective instructions, and 8 commented on workshop processes (e.g., "It validated a lot of strategies I was already using”). Of the 19 teachers who shared the most important thing they learned from the stress management workshop, 11 nominated how to restructure maladaptive thoughts, 3 nominated how to identify thoughts, feelings, and behaviors, and 6 commented on other topics (e.g., "Talking points for kids who are worried about summer - such great ideas").

\section{General Discussion}

These two community-engaged research studies examined perceptions of psychoeducational workshops developed to improve parents and teachers' mental health literacy. Findings showed that parents and teachers perceived the strategies covered in these workshops to be acceptable, appropriate, and feasible. There was also considerable overlap between the strategies that parents and teachers endorsed learning and the strategies covered in these workshops, indicating that these workshops were relatively successful in teaching strategies for promoting mental and behavioral health to parents and teachers. These results suggest that psychoeducation workshops developed and implemented by community academic partners have potential for enhancing parents and teachers' mental health literacy, which is likely to positively impact youth well-being and functioning. The following are some lessons learned from piloting these workshops to inform future efforts for promoting mental and behavioral health in schools.

Lesson \#1 -Partner with stakeholders to extend the reach of mental health resources. The COVID-19 pandemic caused unprecedented disruptions in schooling and created compounding stressors for students, parents, and teachers (APA, 2021). Attending a psychoeducational workshop could plausibly be perceived as a burden during a time of substantial distress and exhaustion (Fauville et al., 2021; Klapproth et al., 2020). Instead, parents and teachers endorsed 
positive perceptions of these psychoeducational workshops, likely as a result of several decisions made collaboratively by community academic partners. For instance, the idea to host psychoeducational workshops was initiated by school principals. Accordingly, the research team may have been seen as responding to a perceived need as opposed to imposing a separate agenda. The psychoeducational workshops were also scheduled with consideration of parents and teachers' needs (e.g., scheduling workshops for teachers during staff meetings to make efficient use of teachers' limited time and to avoid adding to their already full workloads). Considering bridging factors by partnering with school stakeholders on this initiative meaningfully facilitated the implementation of psychoeducational workshops for these particularly impacted groups.

Lesson \#2 - Identify for whom you are designing mental health resources. School climate and culture are influenced by students, parents, teachers, and school administrators - all of whom have different priorities with regard to mental and behavioral health promotion. As an example, school principals requested psychoeducational workshops for teachers after attending similar psychoeducational workshops for parents on behavior management. School principals reasoned that behavior management workshops for teachers would likely prove helpful in addressing some of the challenges of online learning. Although our findings indicate that teachers appreciated learning classroom management strategies, particularly how to more effectively praise appropriate student behavior, teachers expressed wanting more resources on stress management. This feedback led to discussions among community academic partners about the relative advantage of covering additional classroom management strategies versus stress management strategies and ultimately led to the development of the stress management workshop for teachers. School administrators' responsiveness to the needs and preferences of parents and teachers was 
also likely reflected in their favorable school climate scores. As noted by others, it is critical to identify for whom mental health resources are being designed, as the target stakeholder group should inform resource development, dissemination, and implementation (Lyon \& Koerner, 2016). Relatedly, conducting an initial needs assessment and gathering iterative feedback from the target stakeholder group (or considering the organizational context) is imperative for ensuring that mental health resources are acceptable, appropriate, and feasible.

Lesson \#3 - Gather feedback to continually improve mental health resources. There is a robust literature showing that gathering and incorporating feedback can improve the quality and effectiveness of mental health resources (Bickman, 2008; Douglas et al., 2016; Lyon \& Lewis, 2016). For this study, the research team encouraged parents and teachers to complete a brief online survey about their experience after each psychoeducational workshop and refined future workshops based on their responses. This feedback loop led not only to improved acceptability, appropriateness, and feasibility scores over time but also to invitations for the research team to partner with more than one dozen additional schools and community mental health agencies to implement psychoeducational workshops and other outreach programs. There is likely a great need for mental and behavioral health promotion programs (Gruber et al., 2020), especially as communities recover from the stressors caused by the COVID-19 pandemic, and attending to intervention factors as well as the process of implementing those interventions will be integral to their success.

\section{Limitations}

One study limitation is that a relatively small proportion of the parents and teachers who attended the workshops completed the questionnaire, raising the possibility of self-selection bias. Another limitation is that these workshops were piloted at up to four schools in northern 
California, so it is possible that the parents and teachers in our sample may not be representative of parents and teachers in other areas of the country. Additionally, these workshops were held during a school year that was characterized by rapidly changing public health policies, which may have impacted engagement in these psychoeducational workshops. For instance, two schools elected to reschedule or cancel psychoeducational workshops for parents in spring 2021 upon being tasked to transition back to in-person instruction. Furthermore, the impact of these workshops on mental and behavioral health is presently unknown, as these outcomes were not assessed in these studies. Notably, effect sizes of universal mental health promotion programs are typically small (e.g., Tanner-Smith et al., 2018), so assessing the impact of psychoeducational workshops on mental and behavioral health may present only a partial picture of their utility. Rather, the benefit of psychoeducational workshops stems from their potential to promote recognition and prevention of mental and behavioral health problems, which may be best assessed by examining service and implementation outcomes (e.g., Proctor et al., 2011). Accordingly, findings indicate that these psychoeducational workshops for parents and teachers hold promise and, given trends in pandemic-related stress (APA, 2021), are likely to be beneficial during the ongoing COVID-19 pandemic and beyond. Future research should investigate methods for improving the sustainability of implementing mental and behavioral health promotion programs (Sustainability phase), as well as for scaling the reach of such programs (e.g., through community-based programming and/or digital solutions; Bickman, 2020).

\section{Conclusion}

These studies indicate that there is value in establishing community academic partnerships and developing psychoeducation workshops intended to improve parents and 
teachers' mental health literacy. Enhancing parents and teachers' ability to recognize and respond to mental and behavioral health problems has long been proposed as a strategy for promoting universal well-being and functioning (Jorm, 2012) and is likely to prove particularly beneficial as the world recovers from the compounding stressors brought by the COVID-19 pandemic (Gruber et al., 2020). Yet, this substantial task may be easier said than done. Promoting mental and behavioral health in schools is a complex mission requiring coordinated efforts, as well as consideration of the sociopolitical context, school context, bridging factors, and intervention factors. Through community academic partnerships, we can leverage the scientific and local expertise of students, parents, teachers, school administrators, and clinical scientists to progress toward increasing wellness in schools. 


\section{References}

Aarons, G. A., Hurlburt, M., \& Horwitz, S. M. (2011). Advancing a conceptual model of evidence-based practice implementation in public service sectors. Administration and Policy in Mental Health and Mental Health Services Research, 38(1), 4-23. https://doi.org/10.1007/s10488-010-0327-7

American Psychological Association. (2021). One year later, a new wave of pandemic health concerns. Retrieved from http://www.apa.org/news/press/releases/stress/2021/one-yearpandemic-stress

Bickman, L. (2008). A measurement feedback system (MFS) is necessary to improve mental health outcomes. Journal of the American Academy of Child and Adolescent Psychiatry, 47(10), 1114-1119. doi: 10.1097/CHI.0b013e3181825af8

Bickman, L. (2020). Improving mental health services: A 50-year journey from randomized experiments to artificial intelligence and precision mental health. Administration and Policy in Mental Health and Mental Health Services Research, 47(5), 795-843. https://doi.org/10.1007/s10488-020-01065-8

Boustani, M. M., Frazier, S. L., Chu, W., Lesperance, N., Becker, K. D., Helseth, S. A., ... \& Chorpita, B. F. (2020). Common elements of childhood universal mental health programming. Administration and Policy in Mental Health and Mental Health Services Research, 47, 475-486. https://doi.org/10.1007/s10488-020-01023-4

Brown, S. M., Doom, J. R., Lechuga-Peña, S., Watamura, S. E., \& Koppels, T. (2020). Stress and parenting during the global COVID-19 pandemic. Child Abuse \& Neglect, 110, 104699. https://doi.org/10.1016/j.chiabu.2020.104699

California Department of Education (2020). DataQuest. 2020-21 enrollment by ethnicity. 
Retrieved from https://dq.cde.ca.gov/dataquest/dqcensus/

Douglas, S., Button, S., \& Casey, S. E. (2016). Implementing for sustainability: Promoting use of a measurement feedback system for innovation and quality improvement.

Administration and Policy in Mental Health and Mental Health Services Research, 43(3), 286-291. doi: 10.1007/s10488-014-0607-8

Fauville, G., Luo, M., Muller Queiroz, A. C., Bailenson, J. N., \& Hancock, J. (2021). Nonverbal mechanisms predict zoom fatigue and explain why women experience higher levels than men. Available at SSRN 3820035.

Gruber, J., Prinstein, M. J., Clark, L. A., Rottenberg, J., Abramowitz, J. S., Albano, A. M., Aldao, A., Borelli, J. L., Chung, T., Davila, J., Forbes, E. E., Gee, D. G., Hall, G. C. N., Hallion, L. S., Hinshaw, S. P., Hofmann, S. G., Hollon, S. D., Joormann, J., Kazdin, A. E., ... Weinstock, L. M. (2021). Mental health and clinical psychological science in the time of COVID-19: Challenges, opportunities, and a call to action. American Psychologist, 76(3), 409-426. https://doi.org/10.1037/amp0000707

Gulliver, A., Griffiths, K. M., \& Christensen, H. (2010). Perceived barriers and facilitators to mental health help-seeking in young people: A systematic review. BMC Psychiatry, 10(1), 113. https://doi.org/10.1186/1471-244X-10-113

Jorm, A. F. (2012). Mental health literacy: Empowering the community to take action for better mental health. American Psychologist, 67(3), 231-243. https://doi.org/10.1037/a0025957

Jorm, A. F., Christensen, H., \& Griffiths, K. M. (2006). The public's ability to recognize mental disorders and their beliefs about treatment: changes in Australia over 8 years. Australian \& New Zealand Journal of Psychiatry, 40(1), 36-41. https://doi.org/10.1080/j.14401614.2006.01738.x 
Klapproth, F., Federkeil, L., Heinschke, F., \& Jungmann, T. (2020). Teachers' experiences of stress and their coping strategies during COVID-19 induced distance teaching. Journal of Pedagogical Research, 4(4), 444-452. https://doi.org/10.33902/JPR.2020062805

Kelly, C. M., Jorm, A. F., \& Wright, A. (2007). Improving mental health literacy as a strategy to facilitate early intervention for mental disorders. Medical Journal of Australia, 187(S7), S26-S30. https://doi.org /10.5694/j.1326-5377.2007.tb01332.x

Lasecke, M., Baeza-Hernandez, K., Dosovitsky, G., DeBellis, A., Bettencourt, B., Park, A. L., \& Bunge, E. L. (2022). Disseminating online parenting resources in the community during the COVID-19 pandemic: Lessons learned. Journal of Community Psychology. https://doi.org/10.1002/jcop.22788

Lyon, A. R., \& Koerner, K. (2016). User-centered design for psychosocial intervention development and implementation. Clinical Psychology: Science and Practice, 23(2), 180200. https://doi.org/10.1111/cpsp.12154

Lyon, A. R., \& Lewis, C. C. (2016). Designing health information technologies for uptake: development and implementation of measurement feedback systems in mental health service delivery. Administration and Policy in Mental Health and Mental Health Services Research, 43(3), 344-349. doi:10.1007/s10488-015-0704-3

Martinez, J. I., Lau, A. S., Chorpita, B. F., Weisz, J. R., \& Research Network on Youth Mental Health. (2017). Psychoeducation as a mediator of treatment approach on parent engagement in child psychotherapy for disruptive behavior. Journal of Clinical Child \& Adolescent Psychology, 46(4), 573-587. https://doi.org/10.1080/15374416.2015.1038826

Moullin, J. C., Dickson, K. S., Stadnick, N. A., Rabin, B., \& Aarons, G. A. (2019). Systematic review of the exploration, preparation, implementation, sustainment (EPIS) framework. 
Implementation Science, 14(1), 1-16. https://doi.org/10.1186/s13012-018-0842-6

Neece, C. L., Green, S. A., \& Baker, B. L. (2012). Parenting stress and child behavior problems: A transactional relationship across time. American Journal on Intellectual and Developmental Disabilities, 117(1), 48-66.

New Jersey Department of Education. (2014). New Jersey School Climate Survey. Retrieved from https://www.state.nj.us/education/students/safety/behavior/njscs/

Osgood, K., Sheldon-Dean, H., \& Kimball, H. (2021). 2021 Children's mental health report: The impact of the COVID-19 Pandemic on children's mental health what we know so far. child mind institute. Retrieved from https://childmind.org/awarenesscampaigns/childrens-mental-health-report/2021-childrens-mental-health-report/

Pressley, T. (2021). Factors contributing to teacher burnout during COVID-19. Educational Researcher, 50(5), 325-327. https://doi.org/10.3102/0013189X211004138

Proctor, E., Silmere, H., Raghavan, R., Hovmand, P., Aarons, G., Bunger, A., ... \& Hensley, M. (2011). Outcomes for implementation research: Conceptual distinctions, measurement challenges, and research agenda. Administration and Policy in Mental Health and Mental Health Services Research, 38(2), 65-76. https://doi.org/10.1007/s10488-010-0319-7

Ravens-Sieberer, U., Kaman, A., Erhart, M., Otto, C., Devine, J., Löffler, C., ... \& Hölling, H. (2021). Quality of life and mental health in children and adolescents during the first year of the COVID-19 pandemic: Results of a two-wave nationwide population-based study. European Child \& Adolescent Psychiatry, 1-14. https://doi.org/10.1007/s00787-02101889-1

Regan, J. M. (2014). Client report of session content in an effectiveness trial: In search of efficient fidelity measurement. University of California, Los Angeles. 
Rosen, M. L., Rodman, A. M., Kasparek, S. W., Mayes, M., Freeman, M. M., Lengua, L. J., ... \& McLaughlin, K. A. (2021). Promoting youth mental health during the COVID-19 pandemic: A longitudinal study. PloS One, 16(8), e0255294. https://doi.org/10.1371/journal.pone.0255294

Schlegelmilch, J., \& Douglas, C. (2020). Initial coronavirus disease-2019 closure strategies adopted by a convenience sample of US school districts: Directions for future research. Disaster Medicine and Public Health Preparedness, 14(3), e17-e18. https://doi.org/10.1017/dmp.2020.147

Tanner-Smith, E. E., Durlak, J. A., \& Marx, R. A. (2018). Empirically based mean effect size distributions for universal prevention programs targeting school-aged youth: A review of meta-analyses. Prevention Science, 19(8), 1091-1101. https://doi.org/10.1007/s11121018-0942-1

Taylor-Rodgers, E., \& Batterham, P. J. (2014). Evaluation of an online psychoeducation intervention to promote mental health help seeking attitudes and intentions among young adults: Randomised controlled trial. Journal of Affective Disorders, 168, 65-71. https://doi.org/10.1016/j.jad.2014.06.047

Weiner, B. J., Lewis, C. C., Stanick, C., Powell, B. J., Dorsey, C. N., Clary, A. S., Boynton, M. H., Halko, H. (2017). Psychometric assessment of three newly developed implementation outcome measures. Implementation Science, 12(1), 1-12. https://doi.org/10.1186/s13012017-0635-3

Weisz, J. R., Vaughn-Coaxum, R. A., Evans, S. C., Thomassin, K., Hersh, J. Lee, E. H., Ng, M. Y., Lau, N., Raftery-Helmer, J. N., \& Mair, P. (2019). Efficient monitoring of treatment response during youth psychotherapy: Development and psychometrics of the behavior 
and feelings survey. Journal of Clinical Child and Adolescent Psychology, 49(6), 737751. https://doi.org/10.1080/15374416.2018.1547973 
Figure 1

Applying the EPIS framework to implement psychoeducational workshops

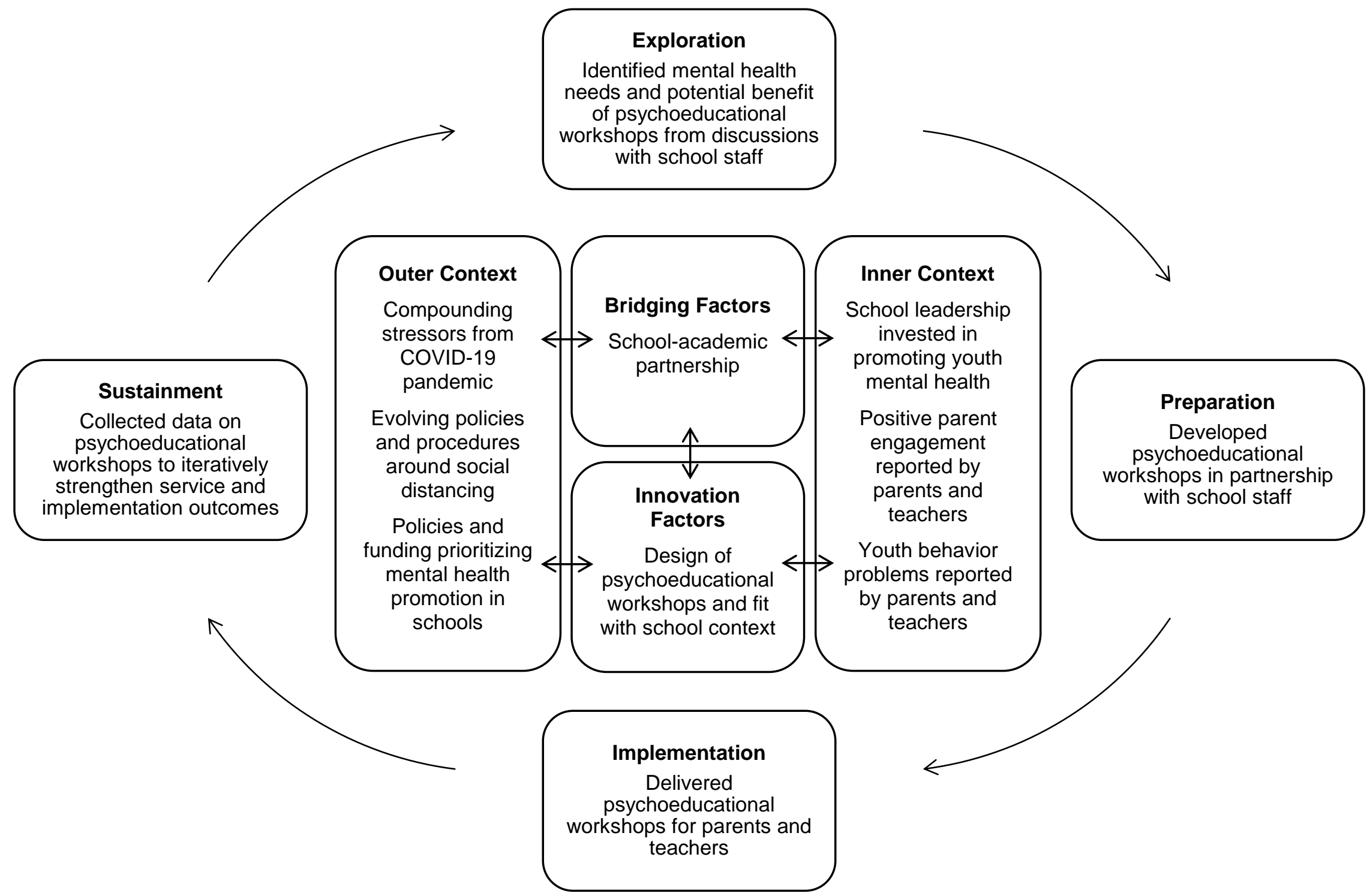


Table 1

School demographics, climate, and workshop participation

\begin{tabular}{|c|c|c|c|c|c|c|c|}
\hline \multirow[t]{2}{*}{ School } & \multirow{2}{*}{$\begin{array}{l}\text { Student } \\
\text { Ethnicity/Race }\end{array}$} & \multicolumn{3}{|c|}{ Parent } & \multicolumn{3}{|c|}{ Teacher } \\
\hline & & $\begin{array}{l}\text { School } \\
\text { Climate }\end{array}$ & $\begin{array}{c}\text { \# of } \\
\text { Workshops }\end{array}$ & $\begin{array}{c}\text { Workshop } \\
\text { Attendance } \\
M(S D)\end{array}$ & $\begin{array}{l}\text { School } \\
\text { Climate }\end{array}$ & $\begin{array}{c}\text { \# of } \\
\text { Workshops }\end{array}$ & $\begin{array}{c}\text { Workshop } \\
\text { Attendance } \\
M(S D)\end{array}$ \\
\hline $\begin{array}{l}\text { School A } \\
\text { 6th-8th }\end{array}$ & $\begin{array}{l}43 \% \mathrm{H} / \mathrm{L} \\
25 \% \text { White } \\
16 \% \text { A/PI } \\
14 \% \text { Multiracial } \\
2 \% \text { Black }\end{array}$ & 83.7 & $\begin{array}{l}4 \text { in English } \\
5 \text { in Spanish }\end{array}$ & $5.11(2.93)$ & 68.1 & 2 in English & $46.50(2.12)$ \\
\hline $\begin{array}{l}\text { School B } \\
\text { K-5th }\end{array}$ & $\begin{array}{l}65 \% \mathrm{H} / \mathrm{L} \\
22 \% \text { White } \\
10 \% \text { Multiracial } \\
3 \% \text { A/PI }\end{array}$ & 83.3 & $\begin{array}{l}3 \text { in English } \\
3 \text { in Spanish }\end{array}$ & $11.17(2.79)$ & 81.6 & 1 in English & $20.00(--)$ \\
\hline $\begin{array}{l}\text { School C } \\
\text { K-8th }\end{array}$ & $\begin{array}{l}30 \% \mathrm{H} / \mathrm{L} \\
28 \% \text { A/PI } \\
27 \% \text { White } \\
13 \% \text { Multiracial } \\
2 \% \text { Black }\end{array}$ & 81.3 & $\begin{array}{l}4 \text { in English } \\
2 \text { Spanish }\end{array}$ & $6.67(5.09)$ & -- & -- & -- \\
\hline $\begin{array}{l}\text { School D } \\
\text { K-5th }\end{array}$ & $\begin{array}{l}45 \% \mathrm{H} / \mathrm{L} \\
23 \% \text { White } \\
19 \% \text { A/PI } \\
11 \% \text { Multiracial } \\
2 \% \text { Black }\end{array}$ & 83.3 & $\begin{array}{l}2 \text { in English } \\
1 \text { in Spanish }\end{array}$ & $4.00(1.00)$ & -- & -- & -- \\
\hline
\end{tabular}

Note: $\mathrm{A} / \mathrm{PI}=$ Asian/ Pacific Islander. $\mathrm{H} / \mathrm{L}=$ Hispanic/ Latinx. Student ethnicity/race as reported by the California Department of Education (2020). 
Table 2

Overview of workshop content

\begin{tabular}{|c|c|c|c|}
\hline Workshop & Audience & Description & COVID-Related Example \\
\hline $\begin{array}{l}\text { Psychoeducation and } \\
\text { Instructions }\end{array}$ & Parents & $\begin{array}{l}\text { Psychoeducation about disruptive behavior } \\
\text { problems; interactive activity on giving } \\
\text { effective instructions }\end{array}$ & $\begin{array}{l}\text { Parents were prompted to brainstorm an } \\
\text { instruction that they could give their child if } \\
\text { their child walked away from their } \\
\text { computer during a virtual class }\end{array}$ \\
\hline Instructions and Praise & Parents & $\begin{array}{l}\text { Psychoeducation about antecedents, } \\
\text { behaviors, and consequences; interactive } \\
\text { activities on giving effective instructions } \\
\text { and praising appropriate behaviors }\end{array}$ & $\begin{array}{l}\text { Parents were prompted to brainstorm how } \\
\text { they could praise their child for playing } \\
\text { quietly while parents were working from } \\
\text { home }\end{array}$ \\
\hline $\begin{array}{l}\text { Attending/ Ignoring and } \\
\text { Household Rules }\end{array}$ & Parents & $\begin{array}{l}\text { Psychoeducation about differential } \\
\text { reinforcement; interactive activities on } \\
\text { ignoring inappropriate behaviors and } \\
\text { enforcing household rules }\end{array}$ & $\begin{array}{l}\text { Parents were prompted to brainstorm how } \\
\text { they could respond to their child rolling } \\
\text { their eyes upon being instructed to join } \\
\text { their virtual class }\end{array}$ \\
\hline $\begin{array}{l}\text { Punishment and Problem } \\
\text { Solving }\end{array}$ & Parents & $\begin{array}{l}\text { Psychoeducation about positive and } \\
\text { negative punishment; interactive activities } \\
\text { on punishing inappropriate behaviors and } \\
\text { problem solving }\end{array}$ & $\begin{array}{l}\text { Parents were prompted to nominate and } \\
\text { evaluate possible solutions to the problem } \\
\text { of their child's friend being available to } \\
\text { video chat during their child's scheduled } \\
\text { homework time }\end{array}$ \\
\hline Review and Help-seeking & Parents & $\begin{array}{l}\text { Review of behavior management strategies, } \\
\text { with interactive activities; psychoeducation } \\
\text { about seeking professional help }\end{array}$ & $\begin{array}{l}\text { Parents were prompted to brainstorm how } \\
\text { they could respond to their children arguing } \\
\text { with each other throughout the virtual } \\
\text { school day }\end{array}$ \\
\hline
\end{tabular}


Classroom Management
Teachers Psychoeducation about disruptive behavior; interactive activities on giving effective instructions and praising appropriate behaviors

Teachers Psychoeducation about the associations between thoughts, feelings, and behaviors; interactive activity on restructuring maladaptive thoughts
Teachers were prompted to brainstorm an instruction they could give to get their students' attention during a virtual class

Teachers were prompted to catch, check, and change thoughts related to teaching to a class of students who are muted with their cameras off 
Table 3

Parent perceptions of workshop content

\begin{tabular}{|c|c|c|c|c|c|}
\hline Workshop & $\begin{array}{c}\text { Attendance } \\
M(S D)\end{array}$ & $\begin{array}{c}\text { AIM } \\
M(S D)\end{array}$ & $\begin{array}{c}\mathbf{I A M} \\
M(S D)\end{array}$ & $\begin{array}{c}\text { FIM } \\
M(S D)\end{array}$ & Most important thing learned \\
\hline $\begin{array}{l}\text { Psychoeducation } \\
\text { and Instructions }\end{array}$ & $10.50(4.04)$ & $4.13(.31)$ & $4.17(.41)$ & $4.21(.40)$ & $\begin{array}{l}\text { Instructions }(n=3) \text { : "Be specific, don't allow for } \\
\text { interpretation of expectations, give one direction at a time, } \\
\text { make sure you have their attention when you talk to } \\
\text { them." } \\
\text { Other }(n=2) \text { : "I loved the practical information and tips } \\
\text { given." } \\
\text { Praise }(n=1) \text { : "Give positive feedback when they do } \\
\text { good." } \\
\text { Parent-Child Interaction }(n=1) \text { : "Tools for building } \\
\text { parent-child relationships." }\end{array}$ \\
\hline
\end{tabular}

Instructions and $\quad 6.63(4.86) \quad 4.50(.71) \quad 4.13(1.24) \quad 4.50(.71) \quad$ Instructions $(n=1)$ : "How we should communicate with Praise

(1.86) $4.50(.71) \quad 4.13(1.24)-4.50(.71)$ In
our child to bring about the effectiveness of the instruction."

Praise $(n=1)$ : "Praise so that we can encourage the behavior we want from our child."

Other $(n=1)$ : “[Antecedents, behaviors, consequences] framework was interesting."

Attending/

Ignoring and

Household Rules

$7.83(1.94) \quad 4.54(.47) \quad 4.50(.50) \quad 4.25(.54)$

Parent-Child Interaction $(n=2)$ : “Talking through the scenarios was helpful as a means of understanding where to be firm and where to let go so bad behaviors are not perpetuated."

Other $(n=2)$ : "Step by step ways to address these ongoing issues."

Household rules $(n=1)$ : "Learning to establish a few important household rules that can be consistently reinforced." 
Punishment and

Problem Solving

Review and Help-

seeking
Instructions $(n=1)$ : "Be clear and direct when giving directions."

$4.50(4.04) \quad 5.00(.00) \quad 5.00(.00) \quad 4.38(.53) \quad$ Punishment $(n=1)$ : "Be selective in the unwanted behaviors that I want to decrease, and making the punishment for such behaviors mild and brief." Praise $(n=1)$ : "Be cognizant of and praise those behaviors that will decrease those unwanted behaviors." Parent-Child Interaction $(n=1)$ : "It reinforced my thoughts on the correct way to influence good behavior in my child."

$2.50(.71) \quad 5.00(.00) \quad 5.00(.00) \quad 4.75(.00) \quad$ Parent-Child Interaction $(n=1)$ : "Parenting skills takes a lot of practice and sometimes it's about retraining ourselves to think and act differently than what our first reaction or natural tendency might be." 
Table 4

Teacher perceptions of workshop content

\begin{tabular}{|c|c|c|c|c|c|}
\hline Workshop & Attendance & $\begin{array}{c}\text { AIM } \\
M(S D)\end{array}$ & $\begin{array}{c}\text { IAM } \\
M(S D)\end{array}$ & $\begin{array}{c}\text { FIM } \\
M(S D)\end{array}$ & Most important thing learned \\
\hline Classroom Management & 48 & $\begin{array}{c}4.23 \\
(1.04)\end{array}$ & $\begin{array}{l}4.36 \\
(.84)\end{array}$ & $\begin{array}{l}4.41 \\
(.88)\end{array}$ & $\begin{array}{l}\text { Praise }(n=18) \text { : "Give students timely, specific praise. } \\
\text { Deliver it in a way that will be received but will not } \\
\text { embarrass them." } \\
\text { Process }(n=8) \text { : "It validated a lot of strategies I was } \\
\text { already using." } \\
\text { Instructions }(n=5) \text { : "Feedback and instruction need to be } \\
\text { concise and in a positive tone." } \\
\text { Other }(n=3) \text { : "Be positive, encouraging and } \\
\text { compassionate to increase engagement." }\end{array}$ \\
\hline Stress Management & $65^{\mathrm{a}}$ & $\begin{array}{c}4.28 \\
(1.00)\end{array}$ & $\begin{array}{l}4.30 \\
(.98)\end{array}$ & $\begin{array}{l}4.13 \\
(.94)\end{array}$ & $\begin{array}{l}\text { Cognitive restructuring }(n=11) \text { : "Catching, checking } \\
\text { and changing thoughts." } \\
\text { Other }(n=6) \text { : "Talking points for kids who are worried } \\
\text { about summer - such great ideas." } \\
\text { Monitoring }(n=3) \text { : "Resources and strategies for } \\
\text { thoughts, feelings, and behaviors." }\end{array}$ \\
\hline
\end{tabular}

\footnotetext{
${ }^{\text {a }}$ Twenty teachers from an elementary school and 45 teachers from a middle school attended.
} 